\title{
Pengaruh Kepemimpinan Kepala Sekolah, Kompetensi, dan Disiplin Terhadap Kinerja Guru Pada SMA IMTEK Pagedangan Tangerang
}

\author{
Prasetyo Kurniawan ${ }^{1}$. Ana Septia Rahman ${ }^{2}$ \\ Dosen Universitas Pamulang, email : dosen02261@unpam.ac.id
}

\section{ARTICLES \\ INFORMATION}

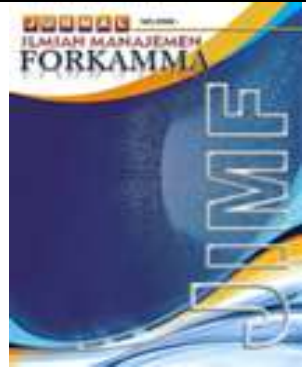

JURNAL ILMIAH MANAJEMEN FORKAMMA

$$
\begin{gathered}
\text { Vol.3, No.3, Juli } 2020 \\
\text { Halaman: } 258-268 \\
\text { ○ LPPM \& FORKAMMA } \\
\text { Prodi Magister Manajemen } \\
\text { UNVERSITAS PAMULANG } \\
\text { ISSN (online) }: 2599-171 X \\
\text { ISSN (print) } \quad: 2598-9545
\end{gathered}
$$

\section{Keyword : \\ Principal Leadership, Competence, Discipline, Teacher Performance}

JEL. classification : O15,

\section{Contact Author : \\ PRODI MAGISTER MANAJEMEN \& FORKAMMA UNPAM \\ JL.Surya Kencana No.1 Pamulang \\ Tangerang Selatan - Banten \\ Telp. (021) 7412566, Fax (021) 7412491 Email: \\ jurnalforkamma.unpam@gmail.com}

ABSTRACT

Tujuan penelitian adalah mengetahui pengaruh Kepemimpinan, kompetensi, dan disiplin terhadap Kinerja Guru Pada SMA IMTEK Pagedangan Tangerang. Metode penelitian dengan metode Asosiatif. Sampel sebanyak 45 responden. Teknik analisis data dengan regresi linier berganda. Hasil penelitian: Makin baik tingkat kepemimpinan kepala sekolah dalam memimpin maka semakin baik pula kinerja guru pada SMA IMTEK Pagedangan Tangerang, Terbukti dari probabilitas parsial $(0,001<0,05)$. Tingginya tingkat kompetensi yang dimiliki oleh para guru maka akan membuat kinerja guru pada SMA IMTEK Pagedangan Tangerang semakin baik pula, Terbukti dari probabilitas parsial $(0,019<0,05)$. Semakin tinggi tingkat disiplinn kerjaa para guru maka akan membuat kinerja guru pada SMA IMTEK Pagedangan Tangerang semakin tinggi, Terbukti dari probabilitas parsial $(0,007<0,05)$. Semakin baik tingkat kepemimpinan kepala sekolah dalam memimpin, tingkat kompetensi yang tinggi dan disiplin kerjaa yang baik maka secara simultan akan membuat peningkatan kinerja guru pada SMA IMTEK Pagedangan Tangerang Terbukti dari probabilitas $(0,000<0,05)$.

The purpose of this study was to determine the effect of leadership, competence, and discipline on teacher performance at the IMTEK Pagedangan Tangerang high school. Research methods with the Associative method. A sample of 45 respondents. Data analysis techniques with multiple linear regression. The results of the study: The better the level of leadership of the principal in leading, the better the performance of teachers in the high school of IMTEK Pagedangan Tangerang, as evidenced by the partial probability $(0.001$ $<0.05)$. The high level of competency of the teachers will make the performance of teachers in Tangerang IMTEK Pagedangan better, too, Proven from partial probabilities $(0.019<0.05)$. The higher the level of work discipline of the teachers, the higher the performance of teachers at the Tangerang Pagedangan IMTEK High School, as evidenced by the partial probability $(0.007$ $<0.05)$. The better the level of leadership of the principal in leading, a high level of competence and good work discipline will simultaneously make an increase in teacher performance in the high school IMTEK Pagedangan Tangerang Proven from the probability $(0,000<0.05$. 


\section{A. PENDAHULUAN}

Penelitian ini dilakukan pada SMA IMTEK Pagedangan Tangerang. Berdasarkan pengamatan penulis, ada masalah dengan kegagalan pekerjaan guru, termasuk: Ada kekurangan pekerjaan karena masih banyak guru yang tidak hadir setiap bulan. Kualitas pekerjaan masih belum maksimal, karena ada guru yang kurang memperhatikan akurasi dan ketertiban dalam pekerjaan mereka. Kerja sama masih rendah, karena masih ada guru yang kesulitan bekerja dengan guru tertentu. Masih ada persentase tanggung jawab yang rendah, ini karena ada guru yang enggan mengakui hasil pekerjaan dan kesalahan dalam membuat keputusan yang salah. Inisiatif masih rendah, seperti dapat dilihat dalam situasi di mana guru tidak memiliki inisiatif pribadi untuk melakukan kegiatan lain di waktu luang mereka, tetapi beberapa guru hanya mengisi waktu kerja mereka dengan hal-hal di luar pekerjaan, seperti bermain internet dan memainkan alat komunikasi.

Kepala sekolah adalah tokoh penting dalam keberhasilan dan kemajuan seolah. Kepemimpinan kepala sekolah di departemen pendidikan sekolah adalah kekuatan pendorong untuk semua sumber daya sekolah dari mana diyakini bahwa mereka akan dapat mempekerjakan kembali guru untuk menjadi lebih efektif, membangun dan mempromosikan hubungan yang baik antara lingkungan sekolah. Untuk menciptakan suasana yang mendukung, menggairahkan, produktif, dan kolaboratif, untuk dapat merencanakan, mengimplementasikan, dan mengevaluasi berbagai jenis kebijakan dan perubahan yang telah dibuat secara efisien dan efektif, semua ditujukan untuk menghasilkan produk atau lulusan berkualitas dengan tingkat keahlian yang lebih tinggi.

Spencer \& Spencer (2007) "kompetensi adalah sebagai karakteristik dasar yang dimiliki oleh seorang individu yang berhubungan secara kausal dalam memenuhi kriteria yang diperlukan dalam menduduki suatu jabatan". Kegiatan penelitian awal yang dilakukan di SMA IMTEK Pagedangan Tangerang memperlihatkan banyak guru yang masih menggunakan metode-metode yang lama sehingga interaksi dengan siswa tidak begitu menyatu, selain itu banyak guru yang memiliki aktifitas lain sehingga membuat guru memiliki waktu terbatas untuk mengumpulkan kegiatan kelas untuk menigkatkan kompetensi profesionalnya.

Selain itu, disiplin juga memiliki efek mendalam pada kinerja guru, dan tanpa disiplin guru tidak akan dapat bekerja seperti yang diharapkan. Secara umum, seorang guru dapat mencapai harapan kerja jika ada ketaatan yang baik. Kedisiplinan menumbuhkan antusiasme untuk bekerja, antusiasme untuk bekerja, dan pencapaian tujuan sekolah, guru dan masyarakat.

\section{Rumusan Masalah}

1. Adakah kepemimpinan kepala sekolah mempengaruhi kinerja guru pada SMA IMTEK Pagedangan Tangerang?

2. Adakah kompetensi mempengaruhi kinerja guru pada SMA IMTEK Pagedangan Tangerang?

3. Adakah disiplin mempengaruhi kinerja guru pada SMA IMTEK Pagedangan Tangerang?

4. Adakah secara simultan kepemimpinan kepala sekolah, kompetensi dan disiplin mempengaruhi kinerja guru pada SMA IMTEK Pagedangan Tangerang?

\section{Tujuan Penelitian}

1. Mengetahui adanya pengaruh kepemimpinan kepala sekolah terhadap kinerja guru pada SMA IMTEK Pagedangan Tangerang.

2. Mengetahui adanya pengaruh kompetensi terhadap kinerja guru pada SMA IMTEK Pagedangan Tangerang.

3. Mengetahui adanya pengaruh disiplin kerja terhadap kinerja guru pada SMA IMTEK Pagedangan Tangerang. 
4. Mengetahui adanya pengaruh simultan kepemimpinan kepala sekolah, kompetensi, dan disiplin kerja terhadap kinerja guru pada SMA IMTEK Pagedangan Tangerang.

\section{B. KAJIAN LITERATUR}

\section{Kepemimpinan Kepala Sekolah}

Kurniawan (2015:3), "Kepemimpinan adalah proses untuk memahami apa yang dilakukan orang secara bersama-sama, sehingga mereka memahami dan mau melakukannya". Rivai (2015:3) mengemukakan bahwa: "Kepemimpinan adalah suatu perilaku dengan tujuan tertentu untuk mempengaruhi aktivitas para anggota kelompok untuk mencapai tujuan bersama yang dirancang untuk memberikan manfaat individu dan organisasi, sehingga dalam suatu organisasi kepemimpinan merupakan faktor yang sangat penting dalam menentukan pencapaian tujuan yang telah ditetapkan oleh organisasi".

\section{Kompetensi}

Uno (2007:63) "Kompetensi merupakan karakteristik yang menonjol bagi seseorang dan menjadi cara-cara berperilaku dan berfikir dalam segala situasi, dan berlangsung dalam periode waktu yang lama". Hutapea \& Thoha (2008:4), "kapasitas yang ada pada seseorang yang bisa membuat orang tersebut mampu memenuhi apa yang disyaratkan oleh pekerjaan dalam suatu organisasi sehingga organisasi tersebut mampu mencapai hasil yang diharapkan".

\section{Disiplin}

Malayu (2016:193), "kedisiplinan adalah kesadaran dan kesediaan seseorang menaati semua peraturan perusahaan dan norma-norma sosial yang berlaku". Sedangkan Prabu (2016:129) "Kedisiplinan dapat diartikan sebagai pelaksanaan manajemen untuk memperteguh pedoman-pedoman organisasi".

\section{Kinerja Guru}

Menurut Prabu (2016:67), "kinerja adalah hasil kerja secara kualitas dan kuantitas yang dicapai oleh seorang pegawai dalam melaksanakan tugasnya sesuai dengan tanggung jawab yang diberikan kepadanya". Edison, dkk (2016:190), "Kinerja adalah hasil dari suatu proses yang mengacu dan diukur selama periode waktu tertentu berdasarkan ketentuan atau kesepakatan yang telah ditetapkan sebelumnya". Sedangkan Malayu (2016:138), "kinerja karyawan suatu hasil yang dicapai oleh seseorang dalam melaksanakan tugas-tugas yang dibebankan kepadanya".

\section{Kerangka Berfikir}

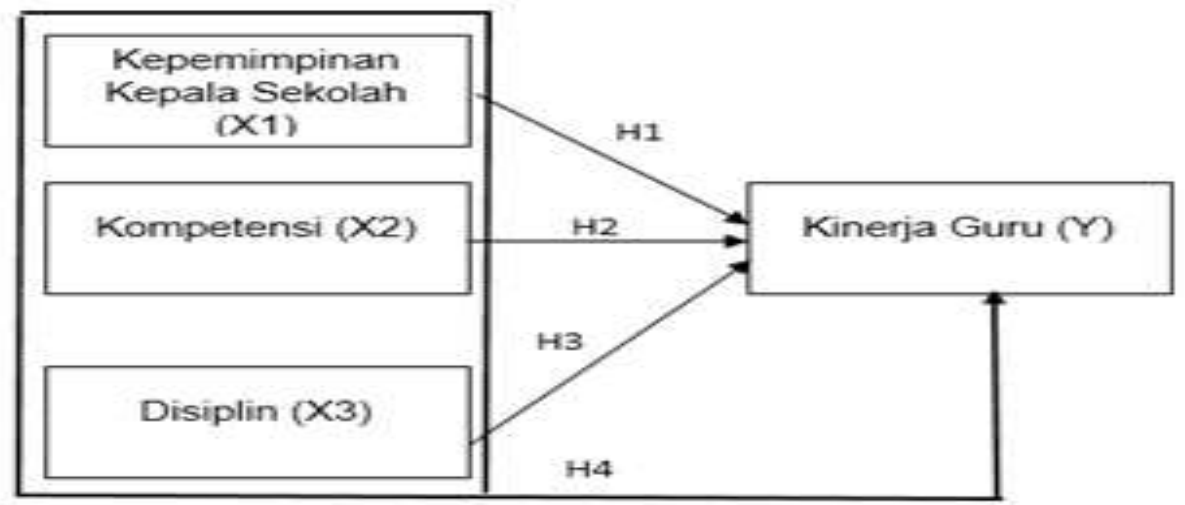

Gambar. 1 Kerangka Berfikir 


\section{METODOLOGI PENELITIAN}

Metode Asosiatif digunakan sebagai metode penelitian ini, menurut Sugiyono (2017:44), "penelitian Asosiatif bertujuan untuk mengetahui pengaruh atau hubungan antara dua variabel lebih".

\section{Populasi dan Sampel}

Populasinya seluruh Guru SMA IMTEK Pagedangan Kabupaten Tangerang sebanyak 45 guru. "Dalam penelitian ini, teknik sampling yang digunakan adalah nonprobability sampling dengan teknik yang diambil yaitu sampling jenuh (sensus)". (Sugiyono, 2015).

\section{Uji Instrument}

\section{Validitas}

Menurut Sugiyono (2017:267), "validitas merupakan derajat ketepatan antara data yang terjadi pada obyek penelitian dengan data yang dapat dilaporkan oleh peneliti".

2. Reliabilitas

Menurut Ghozali (2016:78), "reliabilitas adalah tingkat kehandalan kuesioner, kuesioner yang reliable adalah kuesioner yang apabila dicoba secara berulang-ulang kepada kelompok yang sama akan menghasilkan data yang sama dengan asumsi tidak terdapat perubahan psikologis pada responden".

\section{Uji Asumsi Klasik}

1. Uji Normalitas

Menurut Sugiyono (2017:239), "uji normalitas digunakan untuk mengkaji kenormalan variabel yang diteliti apakah data tersebut berdistribusi normal atau tidak".

2. Uji Multikolinieritas

Menurut Ghozali (2016:82), "uji multikolinearitas bertujuan untuk menguji apakah model regresi ditemukan adanya korelasi antar variabel bebas (independen)".

3. Uji Heteroskedastisitas

Menurut Ghozali (2016:83), "tujuan dari pengujian ini adalah untuk menguji apakah dalam model regresi terjadi ketidak samaan variance dari residual satu pengamatan ke pengamatan lainnya".

\section{Teknik Analisis Data}

1. Regresi Linier Berganda

Menurut Sugiyono (2017:277), "regresi linier berganda bermaksud meramalkan bagaimana keadaan (naik turunnya) variabel dependen, bila dua atau lebih variabel independen sebagai faktor prediktor dimanipulasi (dinaik turunkan nilainya). Jadi analisis regresi berganda akan dilakukan bila jumlah variabel independennya minimal 2".

\section{$Y=a+\beta_{1} X_{1}+\beta_{2} X_{2}+\beta_{3} X_{3}$}

2. Koefisien Determinasi

Menurut Ghozali (2016:97), "Koefisien determinasi $\left(R^{2}\right)$ pada intinya mengukur seberapa jauh kemampuan model dalam menerangkan variasi variabel dependen".

3. Uji t

Menurut Ghozali (2016:84), "Pengujian t-statistik bertujuan untuk menguji ada atau tidaknya pengaruh secara parsial masing-masing variabel independen terhadap variabel dependen". 
4. Uji F

Menurut Ghozali (2016:98), "uji statistik F pada dasarnya menunjukkan apakah semua variabel independen yang dimasukkan dalam model mempunyai pengaruh secara bersama-sama terhadap variabel terikat".

\section{Operasional Variabel Penelitian}

Tabel 1 Operasional Variabel Penelitian

\begin{tabular}{|c|c|c|c|}
\hline Variabel & Dimensi & $\begin{array}{c}\text { Butir } \\
\text { Pertanyaan }\end{array}$ & Skala \\
\hline \multirow{5}{*}{$\begin{array}{c}\text { Kepemimpina } \\
\text { n Kepala } \\
\text { Sekolah }\left(\mathrm{X}_{2}\right) \\
\text { Sumber : } \\
\text { Kartono } \\
(2014: 34)\end{array}$} & $\begin{array}{ll}\text { 1. Kemampuan } & \text { mengambil } \\
\text { keputusan }\end{array}$ & \multirow[t]{5}{*}{$\begin{array}{l}1,2,3,4,5,6 \\
7,8,9,10\end{array}$} & \multirow[t]{5}{*}{ Likert } \\
\hline & 2. Kemampuan memotivasi & & \\
\hline & 3. Kemampuan komunikasi & & \\
\hline & $\begin{array}{l}\text { 4. Kemampuan mengendalikan } \\
\text { bawahan }\end{array}$ & & \\
\hline & 5. Tanggung jawab & & \\
\hline \multirow{5}{*}{$\begin{array}{c}\text { Kompetensi } \\
\left(\mathbf{X}_{2}\right) \\
\text { Sumber: } \\
\text { Mulyasa } \\
(2007: 75)\end{array}$} & 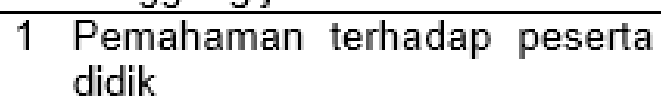 & \multirow[t]{5}{*}{$\begin{array}{l}1,2,3,4,5,6 \\
7,8,9,10\end{array}$} & \multirow[t]{5}{*}{ Likert } \\
\hline & $2 \begin{array}{ll}\text { Kemampuan } \\
\text { pembelajaran }\end{array} \quad$ mengelola & & \\
\hline & 3 Pelaksanaan pembelajaran & & \\
\hline & 4 Evaluasi terhadap hasil belajar & & \\
\hline & 5 Pengembangan peserta didik & & \\
\hline \multirow{4}{*}{$\begin{array}{c}\text { Disiplin Kerja } \\
\left(\mathbf{X}_{3}\right) \\
\text { Sumber: } \\
\text { : Sutrisno } \\
(2016: 94)\end{array}$} & 1. Taat terhadap aturan waktu & \multirow{4}{*}{$\begin{array}{l}1,2,3,4,5,6 \\
7,8,9,10\end{array}$} & \multirow[t]{4}{*}{ Likert } \\
\hline & $\begin{array}{l}\text { 2. Taat terhadap peraturan } \\
\text { sekolah }\end{array}$ & & \\
\hline & $\begin{array}{l}\text { 3. Taat terhadap aturan perilaku } \\
\text { dalam pekerjaan }\end{array}$ & & \\
\hline & $\begin{array}{l}\text { 4. Taat terhadap peraturan lainnya } \\
\text { disekolah }\end{array}$ & & \\
\hline \multirow{3}{*}{$\begin{array}{c}\text { Kinerja Guru } \\
\text { (Y) } \\
\text { Sumber: } \\
\text { Depdiknas } \\
(2008: 22)\end{array}$} & $\begin{array}{l}\text { 1. Perencanaan Program Kegiatan } \\
\text { Pembelajaran }\end{array}$ & \multirow[t]{3}{*}{$\begin{array}{l}1,2,3,4,5,6 \\
7,8,9,10\end{array}$} & \multirow[t]{3}{*}{ Likert } \\
\hline & $\begin{array}{l}\text { 2. Pelaksanaan Kegiatan } \\
\text { Pembelajaran }\end{array}$ & & \\
\hline & $\begin{array}{l}\text { 3. Evaluasi/Penilaian } \\
\text { Pembelajaran }\end{array}$ & & \\
\hline
\end{tabular}

Sumber: data diolah penulis, 2020 


\section{HASIL DAN PEMBAHASAN}

\section{Uji Validitas dan Reliabilitas}

Tabel 2. Hasi Uji Validitas Kepemimpinan $\left(X_{1}\right)$

\begin{tabular}{|c|c|c|c|}
\hline Pernyataan & Nilai $\boldsymbol{r}_{\text {hitung }}$ & Nilai $\mathbf{r}_{\text {tabel }}$ & Keterangan \\
\hline Pernyataan 1 & 0,758 & 0,294 & Valid \\
\hline Pernyataan 2 & 0,703 & 0,294 & Valid \\
\hline Pernyataan 3 & 0,823 & 0,294 & Valid \\
\hline Pernyataan 4 & 0,729 & 0,294 & Valid \\
\hline Pernyataan 5 & 0,755 & 0,294 & Valid \\
\hline Pernyataan 6 & 0,660 & 0,294 & Valid \\
\hline Pernyataan 7 & 0,705 & 0,294 & Valid \\
\hline Pernyataan 8 & 0,697 & 0,294 & Valid \\
\hline Pernyataan 9 & 0,746 & 0,294 & Valid \\
\hline Pernyataan 10 & 0,732 & 0,294 & Valid \\
\hline
\end{tabular}

Sumber: Data Primer diolah dengan SPSS 25 (2020)

Tabel 3 Uji Validitas Kompetensi $\left(\mathbf{X}_{2}\right)$

\begin{tabular}{|c|c|c|c|}
\hline Pernyataan & Nilai $\boldsymbol{r}_{\text {hitung }}$ & Nilai $\mathbf{r}_{\text {tabel }}$ & Keterangan \\
\hline Pernyataan 1 & 0,939 & 0,294 & Valid \\
\hline Pernyataan 2 & 0,935 & 0,294 & Valid \\
\hline Pernyataan 3 & 0,925 & 0,294 & Valid \\
\hline Pernyataan 4 & 0,934 & 0,294 & Valid \\
\hline Pernyataan 5 & 0,928 & 0,294 & Valid \\
\hline Pernyataan 6 & 0,918 & 0,294 & Valid \\
\hline Pernyataan 7 & 0,910 & 0,294 & Valid \\
\hline Pernyataan 8 & 0,858 & 0,294 & Valid \\
\hline Pernyataan 9 & 0,859 & 0,294 & Valid \\
\hline Pernyataan 10 & 0,963 & 0,294 & Valid \\
\hline
\end{tabular}

Sumber: Data Primer diolah dengan SPSS 25 (2020)

Tabel 4. Uji Validitas Disiplin $\left(X_{3}\right)$

\begin{tabular}{|c|c|c|c|}
\hline Pernyataan & Nilai hitung $_{\text {hila }}$ & Nilai $\mathbf{r}_{\text {tabel }}$ & Keterangan \\
\hline Pernyataan 1 & 0,958 & 0,294 & Valid \\
\hline Pernyataan 2 & 0,960 & 0,294 & Valid \\
\hline Pernyataan 3 & 0,970 & 0,294 & Valid \\
\hline Pernyataan 4 & 0,957 & 0,294 & Valid \\
\hline Pernyataan 5 & 0,975 & 0,294 & Valid \\
\hline Pernyataan 6 & 0,949 & 0,294 & Valid \\
\hline Pernyataan 7 & 0,951 & 0,294 & Valid \\
\hline Pernyataan 8 & 0,968 & 0,294 & Valid \\
\hline Pernyataan 9 & 0,974 & 0,294 & Valid \\
\hline Pernyataan 10 & 0,860 & 0,294 & Valid \\
\hline
\end{tabular}

Sumber: Data Primer diolah dengan SPSS 25 (2020) 
Tabel 5. Uji Validitas Kinerja Guru (Y)

\begin{tabular}{|c|c|c|c|}
\hline Pernyataan & Nilai $\boldsymbol{r}_{\text {hitung }}$ & Nilai $\mathbf{r}_{\text {tabel }}$ & Keterangan \\
\hline Pernyataan 1 & 0,894 & 0,294 & Valid \\
\hline Pernyataan 2 & 0,768 & 0,294 & Valid \\
\hline Pernyataan 3 & 0,945 & 0,294 & Valid \\
\hline Pernyataan 4 & 0,804 & 0,294 & Valid \\
\hline Pernyataan 5 & 0,763 & 0,294 & Valid \\
\hline Pernyataan 6 & 0,831 & 0,294 & Valid \\
\hline Pernyataan 7 & 0,859 & 0,294 & Valid \\
\hline Pernyataan 8 & 0,861 & 0,294 & Valid \\
\hline Pernyataan 9 & 0,926 & 0,294 & Valid \\
\hline Pernyataan 10 & 0,679 & 0,294 & Valid \\
\hline
\end{tabular}

Sumber: Data Primer diolah dengan SPSS 25 (2020)

Dari 40 pernyataan disebar kepada guru terlihat bahwa seluruhnya memiliki angka $r_{\text {-hitung }}>r_{- \text {tabel }}(0,294)$ dengan semua item pernyataan valid.

Tabel 6 Hasil Uji Reliabilitas

\begin{tabular}{|l|c|c|}
\hline \multicolumn{1}{|c|}{ Variabel } & Cronbach Alpha & Keputusan \\
\hline Kepemimpinan $\left(\mathrm{X}_{1}\right)$ & 0,895 & Sangat Reliabel \\
\hline Kompetensi $\left(\mathrm{X}_{2}\right)$ & 0,979 & Sangat Reliabel \\
\hline Disiplin Kerja $\left(\mathrm{X}_{3}\right)$ & 0,988 & Sangat Reliabel \\
\hline Kinerja Guru $(\mathrm{Y})$ & 0,939 & Sangat Reliabel \\
\hline
\end{tabular}

Sumber: Hasil Olahan Data SPSS 25 (2020)

Tabel 6 diatas menunjukan kriteria reliabel sudah terpenuhi dengan alpha cronbach diatas nilai kritis.

\section{Asumsi Klasik}

\section{Uji Normalitas}

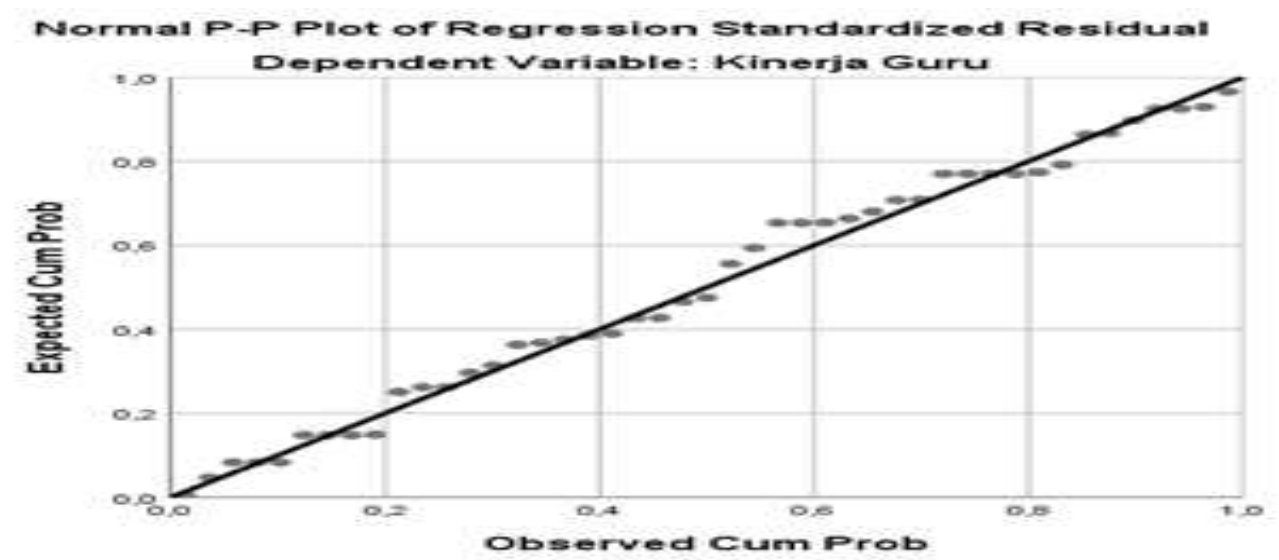

Sumber: Data diolah SPSS versi 25 (2020)

Gambar 2. Uji Normalitas Data P-P Plot 
Penyebaran garis terlihat pada Gambar 2 sudah mengikuti garis diagonal dan tidak ada yang melebar jauh, yang merupakan asumsi normalitas sudah dapat dipenuhi

\section{Uji Multikolineritas}

Tabel 7. Uji Multikolinearitas

\begin{tabular}{|l|c|c|}
\hline \multirow{2}{*}{\multicolumn{1}{|c|}{ Model }} & \multicolumn{2}{c|}{ Collinearity Statistics } \\
\cline { 2 - 3 } & Tolerance & VIF \\
\hline Kepemimpinan & 0,894 & 1,119 \\
\hline Kompetensi & 0,669 & 1,494 \\
\hline Disiplin Kerja & 0,737 & 1,356 \\
\hline
\end{tabular}

a. Dependent Variable: Kineria

Sumber: Hasil Olahan Data SPSS 25 (2020)

Pada tabel 7 menunjukan tidak terdapat adanya suatu gejala-gejala yang memungkinkan adanya multikolineritas karena VIF $<10$ dan toleransinya $>0,10$.

\section{Uji Heteroskedastisitas}

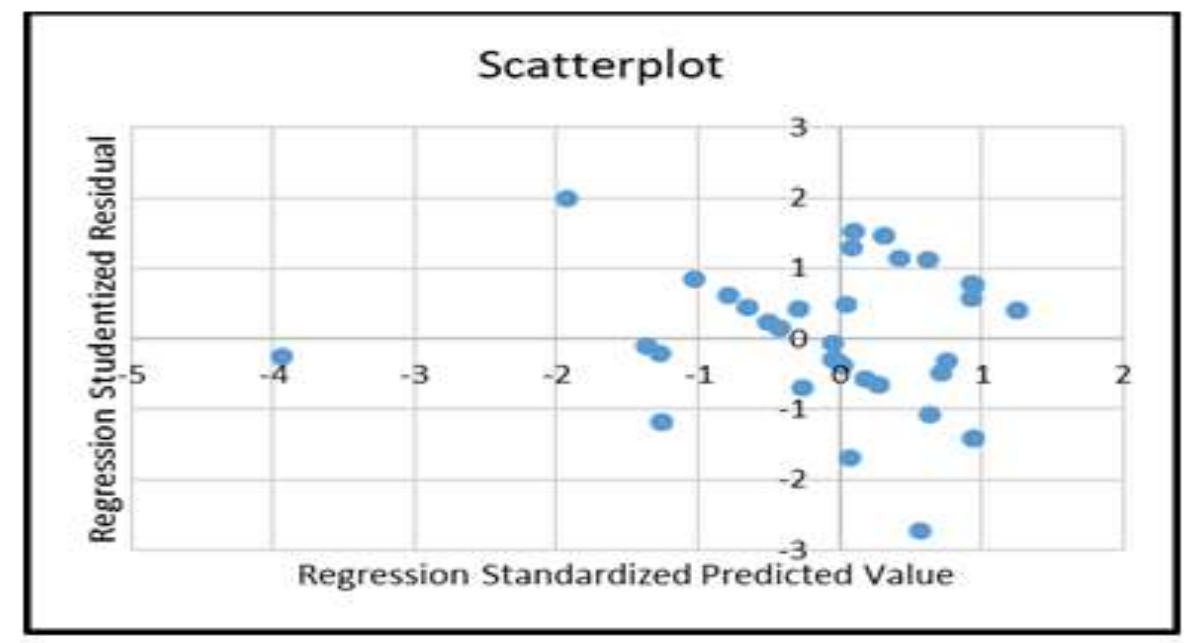

Sumber: Hasil Olahan Data SPSS 25 (2020)

\section{Gambar 3. Pengujian Heteroskedastisitas Dengan Grafik}

Penyebaran data terlihat menyebar secara acak dari bawah maupun dari atas dan tidak ada yang membentuk pola, sehingga data peneitian tidak terjadi heteroskedastisitas.

\section{Regresi Linier Berganda}

Tabel 8. Regresi Linier Berganda

\begin{tabular}{|c|c|c|c|c|c|c|}
\hline \multirow{2}{*}{\multicolumn{2}{|c|}{ Model }} & \multicolumn{2}{|c|}{$\begin{array}{l}\text { Unstandardized } \\
\text { Coefficients }\end{array}$} & $\begin{array}{c}\text { Standardized } \\
\text { Coefficients }\end{array}$ & \multirow[t]{2}{*}{$\mathrm{t}$} & \multirow{2}{*}{ Sig. } \\
\hline & & $B$ & Std. Error & Beta & & \\
\hline \multirow[t]{4}{*}{1} & (Constant) & 14,042 & 4,203 & & 3,341 & 0,002 \\
\hline & Kepemimpinan & 0,352 & 0,095 & 0,400 & 3,703 & 0,001 \\
\hline & Kompetensi & 0,168 & 0,069 & 0,305 & 2,445 & 0,019 \\
\hline & & 62 & 0,058 & 0.335 & 814 & \\
\hline
\end{tabular}

a. Dependent Variable: Kinerja Guru

Sumber: Hasil Olahan Data SPSS 25 (2020) 
$Y=14,042+0,352 X_{1}+0,168 X_{2}+0,162 X_{3}$

1. Nilai konstanta sebesar 14,042 artinya pada saat kepemimpinan kepala sekolah, kompetensi dan disiplin, bernilai nol atau tidak meningkat, maka kinerja guru akan tetap 14,042.

2. Nilai regresii $0,352 X_{1}$ artinya semakin baik tingkat kepemimpinan kepala sekolah dalam memimpin, memberikan teladan, dan mengarahkan para guru dan staff sekolah maka akan membuat peningkatan kinerja guru pada SMA IMTEK Pagedangan Tangerang sebesar 0,352 .

3. Nilai regresi $0,168 \mathrm{X}_{2}$ artinya luasnya pengetahuan kompetensi yang dimiliki guru akan membuat peningkatan kinerja guru pada SMA IMTEK Pagedangan Tangerang 0,168.

4. Nilai regresi $0,162 X_{3}$, artinya guru yang kesesuaian disiplin kerjanya baik maka akan membuat peningkatan kinerja guru pada SMA IMTEK Pagedangan Tangerang 0,162.

\section{Koefisien Determinasi}

Tabel 9. Koefisien Determinasi

\begin{tabular}{|l|l|r|r|r|}
\hline Model & R & R Square & Adjusted R Square & \multicolumn{1}{c|}{$\begin{array}{c}\text { Std. Error of the } \\
\text { Estimate }\end{array}$} \\
\hline 1 &, $756^{\mathrm{a}}$ & 0,572 & 0,541 & 4,70856 \\
\hline
\end{tabular}

a. Predictors: (Constant), Disiplin, Kepemimpinan, Kompetensi

\section{Sumber: Hasil Olahan Data SPSS 25 (2020)}

Dari Tabel 2, diperoleh bahwa angka Rsquare 0,572 berarti bahwa 57,2\% dari variabel kinerja guru dipengaruhi dari variabel bebas, sedangkan sisanya $42,8 \%$ adanya konstruk lain yang tidak termasuk kedalam model ini.

\section{Uji Hipotesis Parsial}

1. Hasil pengujian pada tabel 8 probabilitas $(0,001<0,05)$ menunjukan diterimanya $H_{a 1}$ dan ditolaknya $\mathrm{H}_{01}$ yang berarti kepemimpinan mempengaruhi parsial terhadap kinerja guru.

2. Hasil pengujian pada tabel 8 probabilitas $(0,019<0,05)$ menunjukan diterimanya $H_{a 2}$ dan ditolaknya $\mathrm{H}_{02}$ yang berarti kompetensi mempengaruhi parsial terhadap kinerja guru.

3. Hasil pengujian pada tabel 8 probabilitas $(0,007<0,05)$ menunjukan diterimanya $\mathrm{H}_{\mathrm{a} 3}$ dan ditolaknya $\mathrm{H}_{03}$ yang berarti disiplin mempengaruhi parsial terhadap kinerja guru.

\section{Uji Hipotesis Simultan}

Tabel 10. Uji F Hitung Simultan

\begin{tabular}{|c|l|r|r|r|r|c|}
\hline \multicolumn{2}{|c|}{ Model } & $\begin{array}{c}\text { Sum of } \\
\text { Squares }\end{array}$ & \multicolumn{1}{c|}{ df } & $\begin{array}{c}\text { Mean } \\
\text { Square }\end{array}$ & $F$ & Sig. \\
\hline \multirow{2}{*}{1} & Regression & 1216,120 & 3 & 405,373 & 18,284 &, $000^{\mathrm{b}}$ \\
\cline { 2 - 7 } & Residual & 908,992 & 41 & 22,171 & & \\
\cline { 2 - 7 } & Total & 2125,111 & 44 & & & \\
\hline
\end{tabular}

a. Dependent Variable: Kinerja Guru

b. Predictors: (Constant), Disiplin, Kepemimpinan, Kompetensi

Sumber: Hasil Olahan Data SPSS 25 (2020) 
Tabel 10 menunjukkan bahwa angka probabilitas lebih kecil dan lebih rendah dari 0,01 atau $(0,000<0,01)$, yang berarti diterimanya $H_{a 4}$ dan ditolaknya $H_{04}$ artinya kepemimpinan, kompetensi, dan disiplin mempengaruhi simultan terhadap kinerja guru SMA IMTEK Pagedangan Tangerang.

\section{E. KESIMPULAN}

1. Semakin baik tingkat kepemimpinan kepala sekolah dalam memimpin maka semakin baik pula kinerja guru pada SMA IMTEK Pagedangan Tangerang, Terbukti dari probabilitas parsial $(0,001<0,05)$.

2. Tingginya tingkat kompetensi yang dimiliki oleh para guru maka akan membuat kinerja guru pada SMA IMTEK Pagedangan Tangerang semakin baik pula, Terbukti dari probabilitas parsial $(0,019<0,05)$.

3. Semakin tinggi tingkat disiplinn kerjaa para guru maka akan membuat kinerja guru pada SMA IMTEK Pagedangan Tangerang semakin tinggi, Terbukti dari probabilitas parsial $(0,007<0,05)$.

4. Semakin baik tingkat kepemimpinan kepala sekolah dalam memimpin, tingkat kompetensi yang tinggi dan disiplin kerjaa yang baik maka secara simultan akan membuat peningkatan kinerja guru pada SMA IMTEK Pagedangan Tangerang Terbukti dari probabilitas $(0,000<0,05)$.

\section{DAFTAR PUSTAKA}

Edison, dkk. (2016). "Manajemen Sumber Daya Manusia". Edisi. Pertama. Bandung: Alfabeta.

Hamzah, B. U. (2007). "Teori Motivasi dan Pengukurannya”. Jakarta: Bumi. Aksana.

Hasibuan, M. (2016), "Manajemen Sumber Daya Manusia”. Edisi Revisi. Jakarta: Bumi Aksara.

Hutapea, T. (2008). “Kompetensi Plus”. Jakarta: PT Gramedia Pustaka Utama.

Kurniawan. P. (2020), "Pengaruh Kecerdasan Intelektual Dan Kecerdasan Emosional Terhadap Kinerja Karyawan Pada PT. Bank Rakyat Indonesia (Persero) Cabang Tangerang Merdeka". Jenius, Vol. 3. No. 3.

Kurniawan, P. (2019), "Pengaruh Disiplin Kerja, Motivasi, Dan Komitmen Organisasi Terhadap Kinerja Karyawan Pada PT. Bank Rakyat Indonesia (Persero) Cabang Tangerang Merdeka", Jurnal Ekonomi Efektif, Vol. 1. No. 2.

Kurniawan, P. (2019), Pengaruh Motivasi dan Disipli Kerja Terhadap Produktifitas Kerja Karyawan Pada PT. Daya Perkasa. Jurnal Mandiri. Vol. 2. No.2

Kadim, A., Sunardi, N., \& Husain, T. (2020). The modeling firm's value based on financial ratios, intellectual capital and dividend policy. Accounting, 6(5), 859-870.

Mangkunegara, A. P. (2015). "Manajemen Sumber Daya Manusia Perusahaan", Bandung: PT. Remaja Rosdakarya.

Sunardi, N., \& Lesmana, R. (2020). Pelaksanaan Alokasi Dana Desa Terhadap Manajemen Keuangan Desa dalam Meningkatkan Efektivitas Program Desa Sejahtera Mandiri Di Desa Cihambulu, Kec. Pabuaran, Kab. Subang. Jurnal SEKURITAS (Saham, Ekonomi, Keuangan dan Investasi), 3(3), 277-288.

Rivai, V. (2015), "Manajemen Sumber Daya Manusia Untuk Perusahaan”, Edisi ke 6, Depok: PT. Raja Grafindo Persada. 
Lesmana, R., Sunardi, N., \& Tumanggor, M. (2020). Pelatihan Manajemen dalam Meningkatkan Motivasi Siswa dan Guru SDN 84 Rejang Lebong. Jurnal Abdi Masyarakat Humanis, 1(2).

Sugiyono, (2017), "Metode Penelitian Manajemen”, Bandung: CV Alvabeta.

Sutikno, S. M. (2014). "Pemimpin Dan Gaya Kepemimpinan”, Edisi Pertama. Lombok: Holistica.

Yukl, G. (2015). “Kepemimpinan dalam Organisasi (Leadership in Organization)", (Edisi Ketujuh). Jakarta: PT.Indeks. 